\title{
Works execution organization at reconstruction and renovation of buildings after the fire with usage of slabs lifting method
}

\author{
O.E. Zyma ${ }^{1 *}$, E.V. Dyachenko ${ }^{1}$, R.I. Pahomov ${ }^{1}$, S.M. Zhyhylii ${ }^{1}$ \\ ${ }^{1}$ Poltava National Technical Yuri Kondratyuk University, Poltava, UKRAINE \\ *Corresponding author E-mail: zymaae@gmail.com
}

\begin{abstract}
Works execution organization at reconstruction and renovation of residential and public buildings after the fire for embedded systems with usage of slabs lifting method at restrained urban conditions were considered. The paper suggests usage features of the slabs lifting method at building reconstruction conditions after the fire. The technology of reconstruction with the usage of slabs lifting method allows to practically refuse the use of lifting cranes and to reduce significantly (up to 50\%) the required building area compared with the lifting crane construction methods of embedded structures. It allows to perform the reconstruction without restriction of traffic on adjoining streets and to perform construction in restrained urban conditions.
\end{abstract}

Keywords: Embedded Systems; Fire; Organization; Reconstruction; Slabs Lifting Method.

\section{Introduction}

The problem of fires is becoming global in scope, affecting not only national but also international interests. The disaster at the Chernobyl Nuclear Power Plant, long-term fires at the oil refineries, the burning of large forest areas and landfills convinces us of this.

Each year on Earth there are about 7 million fires. Statistics show that with population growth by $1 \%$, the number of fires increases by about $5 \%$, and losses increase by $10 \%$. According to projections made on the basis of fire statistics, in the world, during the year, 225 thousand people can be killed in fires, 2 million 250 thousand people - get injured, 4,5 million - severe burn injuries. The vast majority of fires (about $75 \%$ ) and the number of killed persons (more than 90\%) are in the residential and public sectors [1]. The number of fires in Ukraine is increasing year by year, and the state of fire safety for 2009-2016 is shown on Figure 1.

According to [1], fires also cause significant material costs, with both direct and indirect costs (Figure 2).

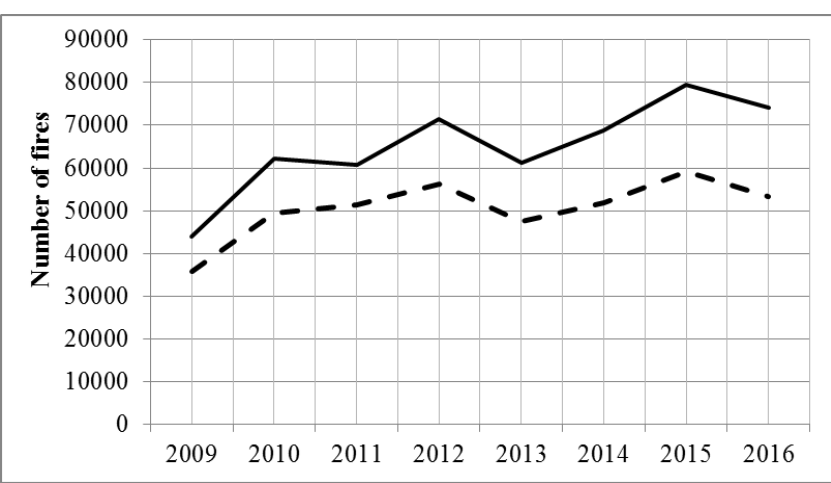

Fig. 1: Dynamics of the number of fires from 2009 to 2016: 1 - total number of fires; 2 - the number of fires in the residental sector

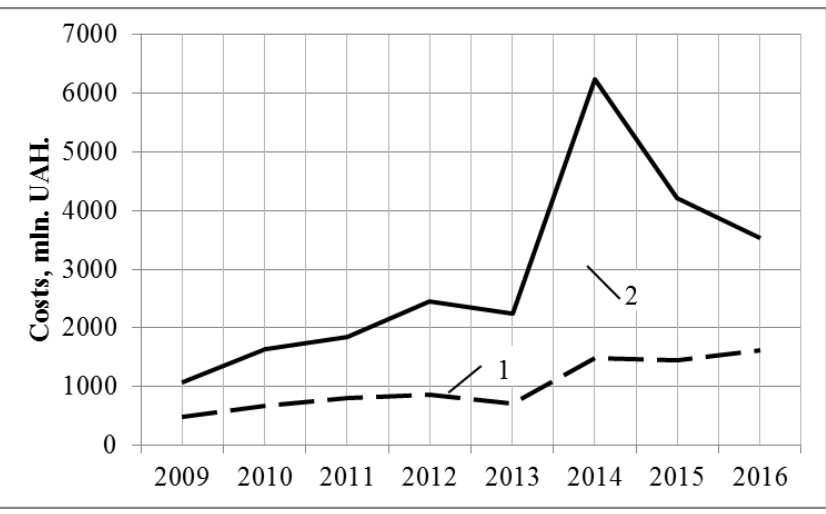

Fig. 2: Costs from fires 2009 - 2016: 1 - direct costs; 2 - indirect costs

According to [2], during 2017, there were 83,116 fires registered in Ukraine. Compared to 2016, there is an increase in the number of fires by $12.0 \%$, direct material damage by $25.3 \%$, indirect by $64.4 \%$, the number of people killed in the fires decreased by $2.8 \%$, the number of people injured in fires increased by $9.1 \%$, the number of destroyed and damaged buildings and structures increased by $17.0 \%$.

Material losses from fires amounted to 7 billion 860 million 225 thousand UAH (direct material damage is 2 billion 38 million 653 thousand UAH, and indirect costs - 5 billion 821 million 572 thousand UAH).

As a result of fires, the number of destroyed or damaged buildings and structures has increased, which justifies the need to assess the state of buildings, building structures and the possibility of their further exploitation.

\section{Problem definition}

Reconstruction of old urban development residential buildings, which, as a rule, have historical significance and create an archi- 
tectural character of the city's central part, is undoubtedly actual. The topicality is conditioned by the necessity of preserving the architectural integrity of historical development and, at the same time, the need for adaptation of planning concepts and buildings constructive concepts to the new operating conditions. The main reasons for the need of reconstruction are the discrepancy of existing planning concepts with modern conditions and the usage of wooden structures as ceiling structures. Due to long operating terms, wooden structures, as a rule, are generally at insufficient condition and require replacement or cannot withstand to the new increased operational loads.

In many cases it is economically feasible and technically possible to restore the operational properties of structures. Therefore, before restoring the building after the fire, it is necessary to conduct a survey to determine the actual bearing capacity of individual building elements and the entire building as a whole, as well as to make recommendations for the strengthening and restoration of damaged structures.

Inspection of buildings after the fire includes a whole range of works, including a visual inspection of the building in order to determine the suitability of the project structural design, measuring the geometric sizes of building structures, taking and laboratory testing of concrete samples of reinforcement, brickwork, etc. The results of the building survey are the basis for choosing methods and technologies for restoring buildings after the fire.

There are various methods and technologies for restoring buildings after the fire $[3,4]$. Conditionally, they could be divided into traditional and innovative.

Among the traditional methods there are methods related to the installation of additional elements on building constructions (steel wallets, belts, beams, etc.). These methods in general effectively cope with the task of strengthening building structures, but after their application the geometry of the building is changed and an additional load on building structures is created. In addition, traditional methods do not differ in the high speed of implementation and require the involvement of a large number of manpower.

The most rapid, effective and cost-effective are the so-called innovative ways of restoring buildings after the fire. Among such methods, there are external reinforcement of building structures with composite materials based on glass or carbon fibers, injection intensive technologies are used for repair of various damage (cracks, bundles) of reinforced concrete structures, shotcrete - the fastest and most effective way to restore the protective layer of concrete. The presented innovative methods don`t create significant additional load on building structures (with the exception of shotcrete) and allow to quickly and effectively carry out the restoration of the bearing capacity of the building or structure with minimal financial costs and without the involvement of a large amount of manpower.

One of the reconstruction methods of such buildings is the construction of embedded systems with the preservation of existing enclosure structures (Figure 3). To the features of works execution at the reconstruction of buildings at restrained urban conditions, especially in the central, historical parts of the cities should include considerably limited size of the building area.

This requirement essentially affects the possibilities of using construction equipment and lifting cranes. In some cases, the usage of lifting cranes requires the restriction or cessation of vehicles for a long time, and sometimes, the usage of lifting cranes is impossible at all. The foregoing lead to refuse of the usage prefabricated reinforced concrete structures and to use monolithic reinforced concrete structures as structures of the built-in frame. However, the usage of monolithic structures still requires the use of lifting cranes for the supply of reinforcement cages and formwork. One of the methods that allows us to almost completely abandon of the lifting cranes usage during the erection of built-in structures is the slabs lifting method [5].

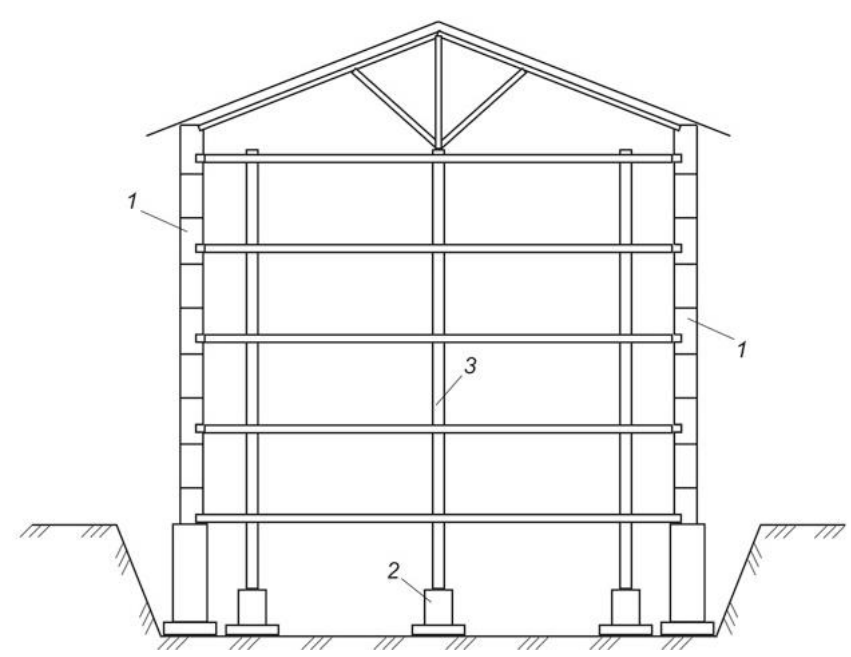

Fig. 3: Building reconstruction with the usage of enclosure structures: 1 existing enclosure structures; 2 - foundation of the embedded system; 3 embedded structures

\subsection{Analysis of recent research and publications}

Recently, due to the actuality of the need for reconstruction of residential and public buildings of the old urban development, a large number of works [6 - 19] devoted to this question, had appeared. In works $[6-10]$ the peculiarities of the reconstruction of foregoing buildings, the problems of using construction equipment in the conditions of the building area limited size are considered, and the usage of prefabricated and monolithic reinforced concrete as a material of embedded structures is compared. It is concluded that the reconstruction of the old urban development buildings by replacing the ceiling structures and construction of built-in structures allows to preserve the architectural character of the cities historical part and at the same time to adapt buildings to the new conditions of exploitation. The works of some authors are often devoted to the issues of the concrete objects reconstruction [11 13], some part of the works is devoted to the strengthening of historic building`s structures [14 - 16]. Works [17 - 19] discuss the general issues of historical building`s reconstruction.

\subsection{Description of general problem unsolved aspects}

Despite the large number of works on article topic, until this time, the method of foregoing building's reconstruction after the fire hasn't been proposed. There was no method that would allow to completely abandon usage of lifting cranes for significantly facilitate of the work`s organization under conditions of the building area limited size and to refuse of the vehicles movement stop. The possibility of lifting slabs method usage for the reconstruction of buildings wasn't considered.

\subsection{The purpose of the paper}

To analyze the peculiarities of lifting slabs method usage for the reconstruction of residential and public buildings after the fire by constructing embedded systems. To identify the benefits of using this building`s reconstruction method in comparison with other methods.

\section{Basic material and results}

As it's known [5], the construction of multistory frame buildings with a monolithic or prefabricated monolithic reinforced concrete frame by the lifting slabs method is to create on the earth surface or on a floor slab panel above the underground part the entire complex of floor slab panels. After floor slab panels installation and attainment required reinforced concrete strength, the floor slab 
panels lifting up to the design position on previously erected columns using lifts.

This method has the following sequence of work: 1) erection of the underground part of the building by the traditional method, that anticipates the erection of column`s foundations, installation of the underground part columns, installation of building`s underground part envelope, floor slab panels, etc. (Figure 4); 2) the arrangement of the stiffening core, that ensures the durability of the building in the longitudinal and crosswise directions. As a rule, a stair enclosure with elevator shaft is placed inside the stiffening core; 3 ) installation, or placement of the ground floor monolithic columns; 4) installation of the floor slab panels complex round the building for the entire building area or section; 5) after the required reinforced concrete strength attainment of the floor slab panels, the lifting of slabs in an intermediate position with the usage of lifts fixed on the columns is accomplished; 6) installation or placement of the next level columns, moving the elevators and floor slab panels lifting; 7) after the lifting of all floor slab panels into the design position, the elevators are removed, next stage is the roof, enclosing structures arrangement, after that general construction works and finishing works are performed.

The advantages of such a method of building construction should include the fact that it can significantly reduce the usage of lifting cranes, and sometimes completely abandon their usage, significantly reduce the building area size; and in addition, due to lack of bearing walls inside the building, this method doesn't impose restrictions on the choice of design decisions.

This method was supposed to be used primarily for new construction, the usage of this method during the reconstruction was not considered.

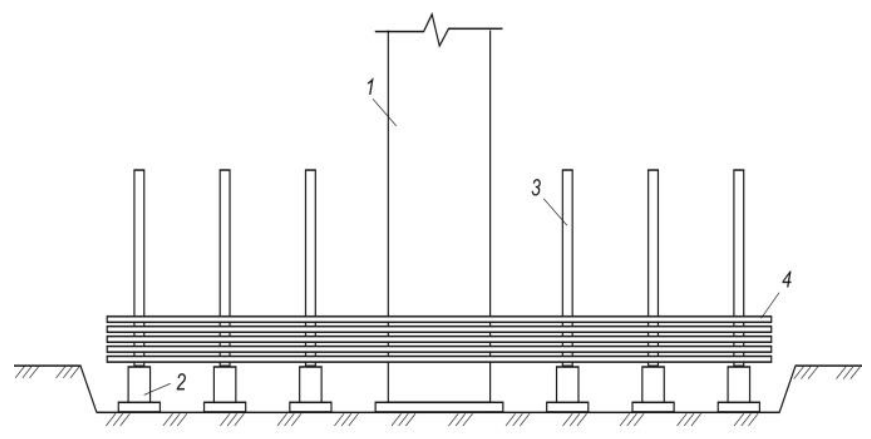

Fig. 4: Erection of the building with the slabs lifting method usage: 1 - stiffening core; 2 - foundations; 3 - columns; 4 - complex of the floor slab panels

From the analysis of this method advantages, it follows that its use during the reconstruction of buildings through the construction of embedded systems would allow for reconstruction without going beyond the constraints of restrained urban development conditions imposed on the construction. The method of floor slab panels lifting due to the refusal of cranes usage would allow reduce the building area size to almost the area size of the reconstructed building; refuse to restrict traffic and pedestrians and the operation of nearby objects.

The structure of the building reconstruction works by the proposed method will be as follows: 1) disassembling of the internal structures of the building. At the same time, disassembly should be conducted with strict sequence observance of the structures disassembling adopted in the technological plans. If necessary, the reinforcement of the enclosing structures is carried out; 2) the soil excavation under the foundations of the embedded system, the installation of monolithic foundations under the embedded structures. If necessary, concrete mixture preparation at the object and feed it with a light-weight concrete pump, located in the dimensions of the building. After the attainment required concrete strength, the waterproofing of the foundations and soil backing with compaction are carried out. If necessary, a reinforced concrete floor of the underground building part is arranged; 3 ) erection of first level monolithic columns. Formwork and reinforce- ment frames are installed from scaffold, the delivery of concrete mixture is carried out by a light-weight concrete pump; 4) installation of monolithic floor slab panel above the underground part of the building. Concrete is delivered centrally to the formwork by a concrete pump, located outside the building; 5) after the attainment required concrete strength of floor slab panel above the underground part, on its surface is arranged one after another the entire complex of floor slab panels (Figure 5). Panels are separated by a separating layer; 6 ) after the attainment required concrete strength, the structures of the scaffold, formwork, prefabricated reinforced frameworks and a light-weight concrete pump are loaded onto the last plate for concreting the next level of columns; 7) elevators for lifting floor slab panels are installed on the headings of the first level columns [5]. Panels are lifted to an intermediate position and fixed (Figure 6);8) concreting of the second level columns is carried out; 9) the lifting of the floor slab panels continues after the attainment required concrete strength of the columns. The last two paragraphs are repeated until the concreting of the last level columns end and the lifting of all floor slab panels in the design position. After that, the joints between columns and slabs, between plates and enclosing structures are packing; the light-weight concrete pump is removed from the surface of the slab by a lifting crane. Installation of the building roofing, internal general construction works, and finishing works are operated by traditional methods.

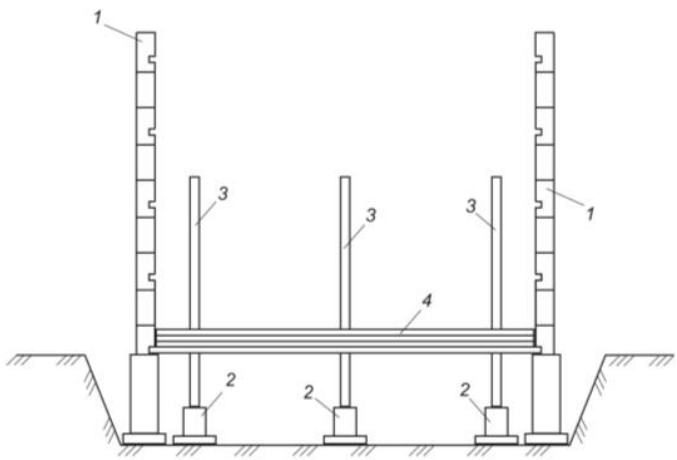

Fig. 5: Installation of embedded frame with usage a lifting slab panels method (stage of floor slab panels concreting): 1 - existing walls; 2 foundations under embedded framework; 3 - columns; 4 - floor slab panels complex

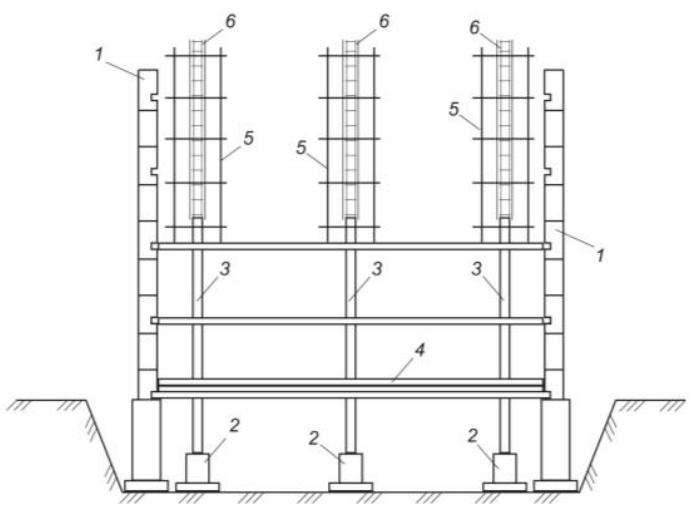

Fig. 6: Installation of embedded frame with usage a lifting slab panels method (stage of second level columns concreting): 1 - existing walls; 2 foundations under embedded framework; 3 - columns; 4 - floor slab panels complex; 5 - scaffold; 6 - column formwork

As can be seen from the given structure of works, the proposed technology of buildings reconstruction allows practically to refuse the use the lifting cranes during the execution of works. It allows to increase the building general plan coefficient of compactness to $60-80 \%$. With the usage of the traditional construction methods, this ratio is about $10-40 \%$. The proposed method obviate the floor slab panel formwork installation and support structures under 
it, as the formwork is pre-concreted slabs. This method allows to significantly reduce the work complexity on the installation of floor slabs.

However, the usage of the lifting slabs method at the construction of embedded systems involves the manual assembly of column`s formwork, installation of reinforcing cages into the formwork, assembly and disassembly of scaffold, installation and removal of lifts.

The most effective method of construction organization is the streaming construction method and this method usage allows for definite significant advantages such as regularity and low intensity of resource consumption, reduction of construction time [11]. However, in the consideration case, the usage of this construction method is complicated by certain conditions. One of these conditions is a relatively small building area size that complicates or makes it impossible to separate the building to the required number of work zones. As a rule, in most cases, such types of buildings could be divided up to a maximum of two work zones that is not enough for the streaming organization of the monolithic structures construction. However, such case does not mean that it is impossible to effectively organize the process of installing embedded systems by usage of lifting slabs method. At the same time, the greatest attention should be paid to the organization of work on the installation of floor slabs, since their share in the total construction complexity of embedded systems is $60-80 \%$. Figure 7 shows an indicative schedule of work on the installation of floor slabs package.

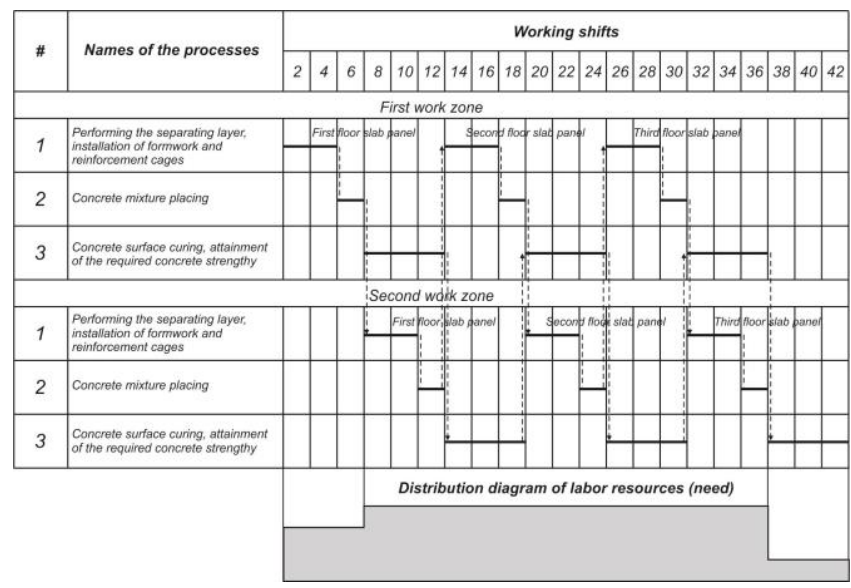

Fig. 7: Work schedule of floor slabs package installation by dividing the building into two work zones: arrowed lines show the transfer of workers

As can be seen from the chart shown in Figure 7, even when dividing the building into two working zones, you can organize the continuous work of the builder's team. Due to this condition the worker`s number, duration of the installation work of the distribution layer between the slabs, the installation of reinforced frames and the concrete mixture placing should be the same with the duration of the concrete surface curing and attainment of the required concrete strength for the work start on the next slab. One of the conditions for such work organization is the use of integrated workers brigade that will combine the installation of reinforced frameworks and the concrete mixture placing. At the same time, as can be seen from the distribution diagram shown in Figure 7, the irregularity coefficient of labor resources usage will be close to one.

\section{Conclusions}

The proposed building`s reconstruction technology can be used (after conducting an economic comparison with other possible methods of reconstruction in these conditions) for the reconstruction of residential and public buildings after the fire by installing embedded systems of monolithic reinforced concrete frame type. The technology of reconstruction with the usage of slabs lifting method allows to practically refuse the use of lifting cranes and to reduce significantly (up to 50\%) the required building area compared with the lifting crane construction methods of embedded structures. It allows to perform the reconstruction without restriction of traffic on adjoining streets and to perform construction in restrained urban conditions.

One of the criteria for the use of such technology is the presence of a building`s stiffening core. As a stiffening core there could be not disassembled walls of stair enclosure.

\section{References}

[1] Fire statistics and their consequences for 2016 [Electronic resource], available online: http://otipb.at.ua/load/statistika_pozhezh_ta_jikh_naslidkiv_ za_2016_rik/24-1-0-5272.

[2] Ukrainian Research Institute of Civil Protection. Fire statistics [Electronic resource], available online: http://undicz.dsns.gov.ua/ua/STATISTIKAPOZHEZH.html.

[3] Panyukov EF Restoration of buildings and structures damaged by fire, Kyiv, (1989), 123 p.

[4] Inspection and restoration of buildings after the fire [Electronic resource], available online: http://www.sdtgroup.ru/articles/obsledovanie-posle-pozhara.

[5] Telichenko VI, Terentyev OM, Lapidus AA, Technology of erection of buildings and structures: Textbook. for construction universities, Moscow: High School, (2004), 446 p.

[6] Osipov AF, Akimov SF, "Features of the volume-planning and structural characteristics of the reconstructed residential buildings in Kyiv", Construction and industrial safety, Vol.6, (2002), pp: 260-265.

[7] Osipov AF, Akimov SF, "Erection of monolithic slabs during the reconstruction of residential buildings, New technologies in construction, Vol.1, (2005), pp: 46-52.

[8] Osipov AF, Akimov SF, "Reconstruction of residential buildings. Methods of erecting monolithic slabs", Science news of Pridniprovia, Vol.3 (2006), pp: 9-15.

[9] Osipov AF, Akimov SF, "Development of organizational and technological models of historical building slabs replacement" Construction and industrial safety, Vol.29, (2009), pp: 101-108.

[10] Voskobiynyk OP, Dyachenko EV, "Features of the technology for the execution of works for the reconstruction of buildings with the usage of embedded systems", Collection of scientific papers (Branch engineering, construction), Vol.33, Poltava: PoltNTU, (2012), pp: 43-48.

[11] Caldwell M, The Fort Stanwix Administrative History: A Superintendent's Perspective, Vol.31, No.2, The Public Historian, (2009).

[12] Korkmaz E, Vatan M, "Retrofitting Deniz Palace historic building for reusing" International journal of electronics; mechanical and mechatronics engineering, Vol.2 Num.3, İstanbul, (2013) pp: 269-278.

[13] Korkmaz E, Vatan M, "Research on Techniques Using For The Retrofitting Of Historical Masonry Structures - Case Study Deniz Palas Building", Proceedings of the CHRESP: 8th EC Conference on Sustaining Europe's Cultural Heritage (10-12.11.2008), Ljubljana, Slovenia, (2008).

[14] Guh TJ, Altoontash A, "Seismic Retrofit of Historic Building Structures", Proceedings of the 8th U.S. National Conference on Earthquake Engineering (April 18-22), SanFrancisco, California, USA, (2006).

[15] El Gawady M, Lestuzzi P, Badoux M, "A Review of Conventional Seismic Retrofitting Techniques for URM", Proceedings of the 13th International Brick and Block Masonry Conference (July 4 - 7), Amsterdam, (2004).

[16] Smith A, Redman T, "A Critical Review of Retrofitting Methods for Unreinforced Masonry Strucutres", Proceedings of the EWB-UK Research Conference, The Royal Academy of Engineering, London, (2009). 
[17] Drury P., McPherson A. Conservation Principles, Policies and Guidance for the Sustainable Management of the Historic Environment, English Heritage, London, (2008), 78 p.

[18] Holland AG, The Reconstruction of Historical Buildings, Virginia Commonwealth University, Richmond, Virginia, (2011), 120 p.

[19] Green M, Building Codes for Existing and Historic Buildings, Hoboken: Wiley, USA, (2012), 247 p. 